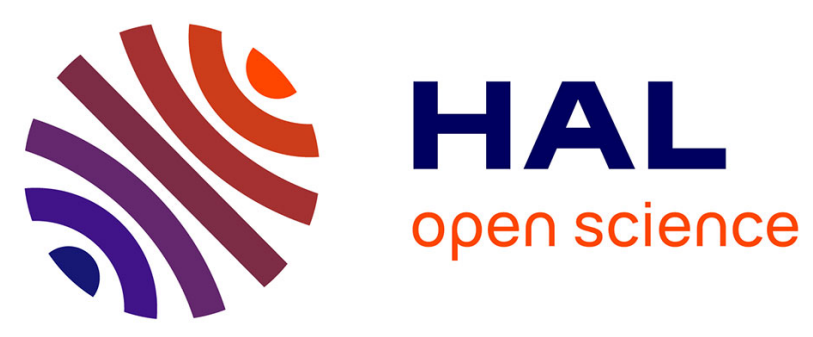

\title{
The consequences of physical post-treatments (microwave and electron-beam) on food/packaging interactions: A physicochemical and toxicological approach
}

Anne-Marie Riquet-Motchidlover, Colette Breysse, Laurence Dahbi, Catherine

Loriot, Isabelle Séverin, Marie-Christine Chagnon

\section{To cite this version:}

Anne-Marie Riquet-Motchidlover, Colette Breysse, Laurence Dahbi, Catherine Loriot, Isabelle Séverin, et al.. The consequences of physical post-treatments (microwave and electron-beam) on food/packaging interactions: A physicochemical and toxicological approach. Food Chemistry, 2016, 199, pp.59-69. 10.1016/j.foodchem.2015.09.034 . hal-01243319

\author{
HAL Id: hal-01243319 \\ https://hal.science/hal-01243319
}

Submitted on 14 Dec 2015

HAL is a multi-disciplinary open access archive for the deposit and dissemination of scientific research documents, whether they are published or not. The documents may come from teaching and research institutions in France or abroad, or from public or private research centers.
L'archive ouverte pluridisciplinaire $\mathbf{H A L}$, est destinée au dépôt et à la diffusion de documents scientifiques de niveau recherche, publiés ou non, émanant des établissements d'enseignement et de recherche français ou étrangers, des laboratoires publics ou privés. 


\title{
The consequences of physical post-treatments (microwave and electron-beam) on food/packaging interactions: A physicochemical and toxicological approach
}

\author{
A.M. Riquet ${ }^{\mathrm{a}, \mathrm{b}, *}$, C. Breysse ${ }^{\mathrm{c}}$, L. Dahbi ${ }^{\mathrm{e}}$, C. Loriot $^{\mathrm{d}}$, I. Severin ${ }^{\mathrm{e}}$, M.C. Chagnon ${ }^{\mathrm{e}}$ \\ a AgroParisTech, Ingénierie Procédés Aliments, UMR1145, Massy, France \\ ' INRA, Ingénierie Procédés Aliments, UMR1145, Massy, France \\ ' CASIMIR, Pôle Technologique d'Auvergne, Aubière, France \\ ${ }^{\mathrm{d}}$ LNE, Trappes, France \\ e Université de Bourgogne, INSERM U866, Derttech “Packtox", Dijon, France
}

\section{A R T I C L E I N F O}

\section{Article history:}

Received 30 January 2015

Received in revised form 7 September 2015

Accepted 10 September 2015

Available online 11 September 2015

\section{Keywords:}

Food packaging

Food safety

By-product components

Migration

Microwave

Electron-beam

Bioassays

\begin{abstract}
A B S T R A C T
The safety of microwave and electron-beam treatments has been demonstrated, in regards to the formation of reaction products that could endanger human health. An integrated approach was used combining the potential toxicity of all the substances likely to migrate to their chemical characterizations. This approach was applied to polypropylene (PP) films prepared with a selection of additives. Components were identified by liquid and gas chromatography using a mass selective detector system. Their potential toxicity was assessed using three in vitro short-term bioassays and their migrations were carried out using a standards-based approach. After the electron-beam treatment some additives decomposed and there was a significant increase in the polyolefin oligomeric saturated hydrocarbons concentration. PP prepared with Irgafos 168 led to a significantly strong cytotoxic effect and PP prepared with Irganox 1076 induced a dose-dependant estrogenic effect in vitro. Migration values were low and below the detection limit of the analytical method applied.
\end{abstract}

(c) 2015 Elsevier Ltd. All rights reserved.

\section{Introduction}

Food packaging materials pose a major challenge to the food industry and for companies making plastic packaging. Manufacturers are facing more and more complex situations (including potential chemical risks) due to the increasing demands of consumers for more sophisticated packaging: more compact, easier to carry and use, microwavable, recyclable active, intelligent and biodegradable. Manufacturers are increasingly turning to products that are more complex in nature. Subsequently, risks should be assessed, as it is known that some polymers may have an impact on both health and the environment because they release substances when used under certain conditions. This is particularly true for the substances concerned because they raise questions about their effects on human health, as widely reported in the media. To achieve public acceptability, and comply with end-user requests, there is a need to find alternatives to replace materials which pose risks

* Corresponding author at: AgroParisTech, Ingénierie Procédés Aliments, UMR1145, Massy, France.

E-mail address: anne-marie.riquet@agroparistech.fr (A.M. Riquet). because they release hazardous substances. The issue of food safety and quality is a core preoccupation for companies producing packaging, particularly for food industries. They must find solutions that ensure good food preservation in accordance with consumer expectations.

National authorities have sought to frame the risk through regulations. The latest regulation concerning plastic and multilayer materials (European Regulation 10/2011) is stricter than the previous one but no guidelines are available because there are areas where scientific knowledge is still lacking. This is particularly the case concerning reactive systems where potential migrants are not the substances that have been introduced in manufacturing, but the reaction products of these substances with their environment, or with each of the substances themselves (compounds' so-called "by-products"). Indeed, materials were subjected to conditions that favor the formation of new potential migrants (posttreatments such as sterilization, cooking) Consequently, the risk is not always limited to the starting materials but sometimes to a number of by-products of an unknown chemical nature which have not been risk assessed. The new regulation requires that the notion of the risk engendered by a substance concerns the 
substance itself, its impurities, and any reaction or degradation products that are foreseeable in the context of their envisaged use. This information is wholly pertinent insofar as potential risks to public health that may result from the migration of these substances. In this case, in order to comply with this regulation, it is imperative to implement methods and develop tools that are sufficiently robust to ensure that manufacturers will be able to guarantee the safety of their products before they are put on the market, and users will be able to check their conformity whatever their future applications (concerning industrial or domestic uses). However, it is particularly difficult to assess the health risks related to by-products because of their chemical nature, toxicity and mechanisms of formation (which depend on the different stages in the life cycle of the material) and because the suitable methods used to identify and assess their migration may not be clearly understood. Therefore, methods for assessing the migration of by-products are still being developed. However, this contamination, when measured qualitatively and quantitatively, does not necessarily mean a risk to human health. Furthermore, a synergistic effect such as a "cocktail effect" may occur.

The originality of the present work is therefore focused on the food safety of plastic packaging using an integrated global approach that combines the potential toxicity of all the substances that are likely to migrate with their chemical characterization to obtain a better understanding of the formation of by-products in food packaging exposed to physical treatments. Its main objective is to anticipate risks and to focus today on some substances of concern that are currently essential for the production or processing of certain materials.

To obtain knowledge on the diversity of behaviors (reactivity) of additives, two particular physical post-treatments were selected which contribute to the generation, or migration, of by-products and which are increasingly being used by both the agro-food industry (packaging decontamination for susceptible products) and by consumers (the reheating of cooked dishes in their original packaging in a microwave oven).

- In the case of microwave heating, the regulations take into account the impact of the high temperatures on migration phenomena but not on the formation of by-products. That is to say the very high temperatures $\left(350-450^{\circ} \mathrm{C}\right)$ the packaging materials can reach during the use of susceptors, i.e. materials used to brown food (Nerín, Fernández, Domeño, \& Salafranca, 2003). The way microwave ovens are used by consumers in their homes have proven to be a key factor in the formation of byproducts and consequently on the safety of packaged foods. The effect of microwave heating on the migration of chemical compounds from the polymeric materials into different food types is important as concerns the selection and manufacturing of suitable packaging materials for microwave use (Bhunia, Sablani, Tang, \& Rasco, 2013; Garrido-Lopez, Sancet, Montano, Gonzalez, \& Tena, 2007; Jeon \& Kim, 2000). Microwaves could selectively increase the diffusivity of small and polar additives in the polymer (Alin \& Hakkarainen, 2011, 2012). They could further influence the polymer matrix, causing localized spot heating effects and the degradation, or consumption, of incorporated additives. In the work presented here, isothermal microwave heating at known temperatures would allow the microwave and thermal effects to be evaluated separately.

- As for irradiation treatments (used, depending on the dose, for the microbial decontamination and reticulation of plastics), the most worrying effect concerns the degradation of polyolefin and polymers with halogenated groups (Davenas et al., 2002; Rivaton, Lalande, \& Gardette, 2004). The role of hydroperoxides in this degradation underlines the importance of stabilizing additives (mainly primary and secondary antioxidants) to maintain the integrity of these materials (Rivaton, Lalande, \& Gardette, 2005). Even if irradiation conditions, including the type of radiation, the dose absorbed, the existence of oxygen and the dose flow rate, play an important role in the formation of by-products (Krzymien, Carlsson, Deschênes, \& Mercier, 2001; Marqué, Feigenbaum, Dainelli, \& Riquet, 1998). In this study, irradiation was performed in air at a dose of $100 \mathrm{kGy}$.

\section{Materials and reagents}

Because of the unknown nature of the by-products (Grob et al., 2010) generated by post-treatments, a purely analytical approach based on an exhaustive identification or quantification of byproducts may be very difficult from an experimental point of view. For this reason, experimental materials were formulated using a set of three fully known, and judiciously chosen, synthetic additives that are found in $95 \%$ of commercialized materials. These additives were added to the material in order to react and were thus identified as being important generators of by-products. In view of the polymer matrix targeted (polypropylene) and the post-treatments identified, focus was on stabilizers.

Irganox 1076 (Octadecyl 3-(3,5-di-tert-butyl-4-hydroxyphenyl) propionate, Irgafos 168 (Tris(2,4-ditert-butylphenyl) phosphite and Tinuvin 326 (Phenol, 2-(5-chloro-2H-benzotriazole-2-yl)-6-(1, 1-dimethylethyl)-4-methyl) came from Ciba Specialty Chemicals (now BASF, Ludwigshafen, Germany).

Experimental polypropylene (PP) films were obtained from a commercial granulate grade (PPH 5060, Total) containing approximately $150 \mathrm{mg} \mathrm{kg}^{-1}$ Irgafos 168 twin screw extrusion technology. A master batch containing additives at $20 \%$ was prepared using a Thermo Haake 16-mm diameter twin screw extruder with a 40 ratio length-to-diameter barrel turning at $300 \mathrm{rpm}$ with a throughput of $600 \mathrm{~g} / \mathrm{h}$. The temperature profile of the six zones of the screw was $180-185-190-200-210-220^{\circ} \mathrm{C}$ and the die was at $210^{\circ} \mathrm{C}$. The second extrusion involved a Rheoscam Scamex 20$\mathrm{mm}$ diameter single barrel extruder with a 12 ratio length-todiameter barrel turning at $80 \mathrm{rpm}$. The temperature profile of the screw zones of was $180-250-240{ }^{\circ} \mathrm{C}$. The flat die, $100 \mathrm{~mm}$ in width, was at $240{ }^{\circ} \mathrm{C}$. It was used to manufacture films $80 \mathrm{~mm}$ in width and $100 \mathrm{~mm}$ in thickness by using a hake chill roll.

In order to facilitate the detection of the breakdown products, three additives (Irgafos 168, Irganox 1076, Tinuvin 326) were admixed at a concentration exceeding the highest level recommended by BASF, the producer of additives (respectively 3, 1.5 and $1.5 \mathrm{wt} \%$ ). As a reference, a film without additives was prepared. All films were wrapped in aluminum foil to prevent absorption of contaminants from ambient air.

\subsection{Post-treatments}

\subsubsection{Electron-beam treated films}

The PP films were activated by electron-beam irradiation (low energy electron accelerator Energy Science LAB-UNIT,). The energy of the electron beam was $165 \mathrm{keV}$, with a beam current of $5 \mathrm{~mA}$ and a speed of $18-\mathrm{ft} \mathrm{min}^{-1}$. Irradiation was performed in air at a dose of $100 \mathrm{kGy}$. In terms of crystalline structure, the impact of electron beam treatment on structural changes in the PP matrix was not really significant when compared to the virgin PP (Riquet, Delattre, Vitrac, \& Guinault, 2013).

\subsubsection{Microwave treated films}

The microwave treatment was carried out on samples prepared as PP trays filled with water at a ratio volume of water $\left(\mathrm{dm}^{3}\right)$ / surface of PP in contact $\left(\mathrm{dm}^{2}\right)$ of $0.14 \mathrm{dm}$ according to the French Normalization XP-ENV 1186. Four temperature sensors placed in different points of the container allowed verification of the 
homogeneity of the temperature during the treatment. After calibrating the microwave oven, output powers of $1100 \pm 4 \mathrm{~W}$ and $796 \pm 2 \mathrm{~W}$ were applied. The treatment was stopped when the temperature of the water reached $95-100{ }^{\circ} \mathrm{C}$, corresponding to contact times of $7 \mathrm{~min}$ at $1100 \mathrm{~W}$ and $10 \mathrm{~min}$ at $800 \mathrm{~W}$.

\subsection{Polymer characterization}

\subsubsection{Mechanical tests}

The PP tensile tests were carried out using a 4507 Instron Universal Testing Machine with a $100 \mathrm{~N}$ load cell (model 4507) at room temperature. The tests were performed at $50 \mathrm{~mm} \mathrm{~min}^{-1}$ on dog-bone samples $55 \mathrm{~mm}$ in length and $2 \mathrm{~mm}$ in width. Tensile stress and deformation at both yields and breaks were measured. All measurements were done in five replicates and the values averaged.

\subsubsection{Differential scanning calorimetry (DSC)}

DSC studies on samples were carried out using a TA instruments DSC Q100. Around $10 \mathrm{mg}$ samples were loaded into the DSC and a complete cycle was performed consisting of an initial heating of between -10 and $220^{\circ} \mathrm{C}$ at $10^{\circ} \mathrm{C} \mathrm{min}^{-1}$, a cooling down to $-10{ }^{\circ} \mathrm{C}$ at $10^{\circ} \mathrm{C} \mathrm{min}^{-1}$ and a second heating to $220^{\circ} \mathrm{C}$ at $10^{\circ} \mathrm{C} \mathrm{min}^{-1}$ under a nitrogen atmosphere. The heat of fusion $(\Delta H f)$ was calculated from the area under the melting peak. The PP crystallinity was obtained from the following expression:

Crystallinity $(\%)=\frac{\Delta H f}{\Delta H f(\text { crys })} \times 100$

where $\Delta H f$ is the heat of fusion of the sample and $\Delta H f$ (crys) is the heat of fusion of $100 \%$ crystalline.

The PP $\Delta H f$ (crys) was taken as $209 \mathrm{~J} \mathrm{~g}^{-1}$.

\subsection{Sample preparation for HPLC-DAD and GC-FID-MS and analyses}

As a first step, two extraction techniques were performed to isolate the substances formed in the polymer matrix: dissolution/ precipitation and accelerated solvent extraction (ASE). Secondly, the extracted non-volatile compounds were characterized by gas chromatography coupled to flame ionization detector and mass spectrometry (GC-FID-MS) and high performance liquid chromatography coupled to diode array detector (HPLC-DAD).

\subsubsection{Dissolution/precipitation technique}

According to Achilias, Giannoulis, and Papageorgiou (2009), the experimental procedure was made up of the following steps: the PP samples $(1 \mathrm{~g})$ were cut into small pieces about $1 \mathrm{~cm}^{2}$ in length and xylene $(20 \mathrm{~mL})$ was added into a flask equipped with a vertical condenser and a magnetic stirrer. The system was heated for $30 \mathrm{~min}$ at $140^{\circ} \mathrm{C}$. Then, the flask was cooled and the solution of the polymer was properly poured into methanol $(250 \mathrm{~mL})$ as a non-solvent. The polymer was re-precipitated, washed, filtrated and dried in an oven at $80^{\circ} \mathrm{C}$ for $24 \mathrm{~h}$. In order to check the reproducibility of the experiments all runs were replicated twice. Extracts were made of up to $20 \mathrm{~mL}$ by nitrogen stream evaporation. Solutions were filtered through a $22 \mu \mathrm{m}$ nylon filter prior to analysis.

\subsubsection{Accelerated solvent extraction}

The PP samples $(0.5 \mathrm{~g})$ were cut approximately to $1 \mathrm{~cm}^{2}$, dispersed in sand to prevent the particles from coalescing during extraction, and placed in a $30 \mathrm{~mL}$ extraction cell. The cell was completely filled with sand in order to reduce the dead volume and thus minimize the amount of solvent required.
Pressurized liquid extractions were performed using a Dionex ASE 200. Extractions were carried out twice using an isopropanol-cyclohexane $(92.5: 7.5, \mathrm{v} / \mathrm{v})$ mixture at $140{ }^{\circ} \mathrm{C}$ and $10.3 \mathrm{~Pa}$ (1500 psi) for $20 \mathrm{~min}$. The percentage of the cell filled with fresh solvent after extraction (flush volume) was $100 \%$ and the purge time was set at $120 \mathrm{~s}$. Extracts were made up to $20 \mathrm{~mL}$ by evaporation under a nitrogen stream. Solutions were filtered through a $22 \mu \mathrm{m}$ nylon filter prior to analysis.

The results obtained for the different conditions were then compared to select the ones which led to the best extraction yield.

\subsubsection{Chromatographic conditions}

2.3.3.1. HPLC-DAD. HPLC analyses were performed with an Agilent 1100 (Hewlett-Packard, Palo Alto, CA, USA) series chromatograph equipped with a diode array detector (DAD). The column was a Waters XTerra C-18, reversed-phase, $5 \mu \mathrm{m}, 10 \mathrm{~cm} \times 4.6 \mathrm{~mm}$ i.d. The analysis of extracts and standards was made on a HPLC system with a mobile phase consisting of 90/10 acetonitrile/tetrahydrofuran and the elution was isocratic.

The wavelength setting on the UV detector was $280 \mathrm{~nm}$, the flow rate was $0.5 \mathrm{~mL} \mathrm{~min}^{-1}$ and the injection volume was $20 \mu \mathrm{L}$. Chromatographic data were collected and processed on a compatible computer with Waters Millenium32 software, version 3.2.

Calibration curves of the I168 and I1010 standards were made by weighing and dissolving three different amounts (200$20,000 \mathrm{ppm}$ ) of each of the antioxidants in ethyl acetate solutions. The calibration curves obtained had a correlation coefficient $\left(R^{2}\right)$ of 0.9989 for I168, 0.9953 for I1076 and 0.9972 for T 326 . All samples run were quantified against these calibration curves.

2.3.3.2. GC-FID-MS. Qualitative analysis was performed in a Hewlett-Packard 6890 gas chromatograph equipped with an FID and a 5975 mass-selective detector and a DB5-MS ( $30 \mathrm{~m} \times 0.32 \mathrm{~mm}, 0.5 \mu \mathrm{m}$ film thickness) capillary column, with helium as a carrier gas (constant flow mode, $1 \mathrm{~mL} \mathrm{~min}^{-1}$ ). The temperature program was the following: initial temperature, $40^{\circ} \mathrm{C}$, was held for $1 \mathrm{~min}$, then raised at $5^{\circ} \mathrm{C} \mathrm{min}^{-1}$ to $290{ }^{\circ} \mathrm{C}$, and then held for $15 \mathrm{~min}$. The temperature of the flame ionization detector (FID) was $305^{\circ} \mathrm{C}$.

Compounds generated by physical treatments were estimated against standard hydrocarbons $\left(\mathrm{C}_{12} \mathrm{H}_{26}\right.$ and $\left.\mathrm{C}_{15} \mathrm{H}_{32}\right)$.

\subsection{Determination of the oligomeric fraction}

The concentrations of polyolefin oligomeric saturated hydrocarbons, before and after irradiation treatments, were carried out by on-line coupled normal phase HPLC-GC-FID following the methodology developed by Biedermann-Brem, Kasprick, Simat, and Grob (2012). Briefly, PP extracts were separated into 6 fractions by normal phase HPLC, followed by complete and automated on-line transfer of these to GC (comprehensive two-dimensional analysis, $\mathrm{HPLC} \times \mathrm{GC})$. The first fraction contained the saturated hydrocarbons termed polyolefin oligomeric saturated hydrocarbons ( $\mathrm{POSH}$ ) and olefinic oligomers.

\subsection{Toxicological study}

The toxic potential of the extracts (and then of all the migrating substances) was assessed from the results of chemical characterisations using three in vitro short-term bioassays. A sensitive sublethal and normalized cytotoxicity test (RNA synthesis inhibition assay) was performed to assess the global cell toxicity and the comet assay was carried out to detect DNA strand breaks as a measure of genotoxic effect induced by the extracts. Both assays were carried out on the human hepatoma cell line HepG2 (Aden, Fogel, Platkin, Damjarov, \& Knowles, 1979). These cells retain many 
of the morphological characteristics of liver parenchymal cells, many of the specialized functions such as the secretion of the major plasma proteins and express a wide variety of liverspecific metabolic enzymes (Kirkland, Kasper, Müller, Corvi, \& Speit, 2008; Knasmuller et al., 2004; Knowles, Howe, \& Aden, 1980; Westerink \& Schoonen, 2007a, 2007b).

The endocrine disruption potential was assessed with the hERalpha-HeLa-9903 cell line derived from a human cervical tumor. This cell line can measure the ability of a test chemical to induce hERalpha-mediated transactivation of luciferase gene expression.

\subsubsection{Cell lines}

Routine monitoring showed that the HepG2 and Hela cells were mycoplasma free (MycoAlert kit from Cambrex, Verviers, France). The HepG2 cell line was obtained from the European Collection of Cell Cultures (ECACC, UK). The cells were grown as monolayer cultures in Minimum Essential Medium (MEM) supplemented with $2 \mathrm{mM}$ L-glutamine, 1\% non-essential amino acids and 10\% Fetal Bovine Serum (FBS) in a humidified atmosphere under $5 \% \mathrm{CO}_{2}$ at $37^{\circ} \mathrm{C}$. All cells used in the experiments were maintained and expanded in cell culture plastic flasks, (Falcon, Dutscher, France). Cells were divided every 7 days at $2.2 \times 10^{6}$ cells $/ 75 \mathrm{~cm}^{2}$ flask by trypsination. Stocks of cells were routinely frozen and stored in liquid $\mathrm{N}_{2}$. Only cells from passages 8 to 17 were used in the experiments.

Stably transfected hER $\alpha$-HeLa-9903 cells were obtained from the Japanese Collection of Research Bioresources (JCRB) Cell Bank. Cells were maintained in Eagles Minimum Essential Medium (EMEM), without Phenol Red, supplemented with kanamycin (60 $\mathrm{mg} \mathrm{L}^{-1}$ ) and $10 \%$ dextran-coated charcoal-treated Fetal Bovine Serum (DCC-FBS; Invitrogen commercial source) in an incubator under $5 \% \mathrm{CO}_{2}$ at $37{ }^{\circ} \mathrm{C}$. Upon reaching $75-90 \%$ confluency, cells were subcultured twice (not more than 10) prior to exposure to the test material extracts.

\subsubsection{Sample preparation for the toxicological test}

Upon their arrival in the lab, the samples were dissolved in ethyl acetate ( 20 or $25 \mathrm{~mL}$ ) after ASE extraction. The solvent was evaporated and each sample was resuspended in DMSO in order to obtain a 50 -fold concentration factor.

\subsubsection{Seeding and treatment}

For the RNA synthesis inhibition and comet assays, HepG2 cells were seeded into 96 -well plates in $200 \mu \mathrm{L}$ of culture medium at a final concentration of $5 \times 10^{4}$ cells/well. After a 28 -h incubation, the medium was removed and the cells were exposed to the test substance for $20 \mathrm{~h}$ in $100 \mu \mathrm{L}$ (comet and RNA synthesis inhibition assays) of fresh complete MEM supplemented with only $0.5 \%$ FBS. DMSO extracts were added to a maximum of $1 \%$ (as a final concentration) in the culture medium, higher concentrations being toxic for the HepG2 cell line.

Positive controls (50 $\mu \mathrm{M}$ methylmethane sulfonate for comet assay) were either dissolved under sterile conditions in DMSO (purity $>99 \%$ ) in such a way that the final concentration of DMSO in the medium was $0.25 \%$, directly added in the culture medium ( $2 \mathrm{mg} \mathrm{L}^{-1}$ potassium dichromate for RNA synthesis assay). Control cells were exposed with the medium containing only vehicle.

Prior to the experiments, Hela-9903 cells were maintained in a culture medium supplemented with a $10 \%$ DCC-FBS charcoal dextran FCS treatment for at least two media-changes. Cells were seeded at a density of $1 \times 10^{4}$ cells per well in $100 \mu \mathrm{L}$ of Phenol Red-free culture medium supplemented with 10\% DCC-FBS in clear bottom white luminometer plates (Greiner Bio-One) and allowed to attach for $3 \mathrm{~h}$.
After incubation, growth medium was replaced with $150 \mu \mathrm{L}$ of dosing medium. Dosing medium consisted of culture medium supplemented with 10\% DCC-FBS and contained the reference compounds at the intended final concentration or sample extracts. The highest volume of the vehicle that the assay system would tolerate was used: DMSO, $0.1 \%(\mathrm{v} / \mathrm{v})$. E2 ( $1 \mathrm{nM})$ was used as a positive control.

All treatments were tested in at least 3 replicates per plate, and each extract was tested in at least two independent experiments.

\subsubsection{Cytotoxicity: RNA synthesis inhibition assay}

The original assay was first described by Fauris, Danglot, and Vilagines (1985) and adapted to HepG2 cells by Valentin-Séverin, Laignelet, Lhuguenot, and Chagnon (2002). Briefly, tritiated uridine was added to the culture medium $(10 \mu \mathrm{L}, 0.3 \mu \mathrm{Ci} /$ well $)$ and its amount of incorporation into the cellular RNA was measured (after $6,12,18,24$ and 30 min uptakes). The RNA synthesis rate was determined by calculating the slope of the straight regression line corresponding to the experimental values. This rate was then plotted against that obtained for the non-toxic blank, arbitrarily fixed at $100 \%$. The results are expressed as a percentage of RNA synthesis in relation to control cells.

\subsubsection{Genotoxicity: comet assay}

The comet assay, also known as the single-cell gel electrophoresis (SCGE) assay, was performed as a sensitive bioassay. The underlying principle is the ability of denatured DNA fragments to migrate during electrophoresis. Electrophoresis can be carried out under highly alkaline conditions $(\mathrm{pH}>12.6)$ in order to detect single and double-strand breaks and alkali-labile lesions. The assay was performed following the protocol of Singh, McCoy, Tice, and Schneider (1988) with some modifications for cell preparation (Valentin-Séverin, Le Hégarat, Lebon, Lhuguenot, \& Chagnon, 2003). Shortly, after the treatment, cell suspensions were prepared by washing the cells with PBS and treating them with trypsin/EDTA for $5 \mathrm{~min}$ at $37^{\circ} \mathrm{C}$. Samples treated with the same concentration were pooled, centrifuged $\left(100 \mathrm{~g}, 5 \mathrm{~min}, 4^{\circ} \mathrm{C}\right)$ and resuspended in $100 \mu \mathrm{L}$ PBS. Fifty microlitre of cells $\left(5 \times 10^{4}\right.$ cells $)$ prepared for analysis were then mixed with $75 \mu \mathrm{L}$ of $0.5 \%$ Low Melting Point (LMP) Agarose at $37^{\circ} \mathrm{C}$. The cell suspension was rapidly spread onto a pre-coated slide, covered with a $25 \mathrm{~mm} \times 25 \mathrm{~mm}$ coverslip, and placed at $4{ }^{\circ} \mathrm{C}$ for $5 \mathrm{~min}$. Coverslips were removed and the slides treated with lysis solution for at least $1 \mathrm{~h}$ at $4^{\circ} \mathrm{C}$. After lysis, slides were exposed to alkaline electrophoresis buffer ( $\mathrm{pH} \mathrm{13)}$ for $40 \mathrm{~min}$ and subjected to electrophoresis for $20 \mathrm{~min}$ (300 mA, $25 \mathrm{mV}$ ). Then, the alkali was neutralized with Tris buffer; the slides rinsed with cold ethanol 96\%, and dried at room temperature. For analysis, the DNA was stained with $80 \mu \mathrm{L}$ of a $5 \mathrm{mg} \mathrm{L}^{-1}$ propidium iodide solution. For evaluation and statistics, one hundred individual comets/slide and two slides/concentration were evaluated under a fluorescence Leica microscope using a $40 \times$ objective and analyzed by using the class system. A score, based on 400 , was given for each analyzed slide $=[(0 \times \%$ of cells in class 0$)+(1 \times \%$ of cells in class 1$)+(2 \times \%$ of cells in class 2$)+(3 \times \%$ of cells in class 3$)+(4 \times \%$ of cells in class 4$)]$. Non-parametric methods were employed for statistical analysis, statistically significant $(P<0.001)$ differences between treatment groups were determined using the Kruskal-Wallis test, followed up by Dunn's post hoc test (all concentrations vs. the control group).

\subsubsection{Endocrine disruption test}

The stably transfected human estrogen receptor-alpha transcriptional activation assay for detection of estrogenic agonistactivity was performed according to the OECD test guideline 455 . After $24 \mathrm{~h}$ of cell exposure, the luciferase activity was determined 
using the SteadyGlo Assay Reagent kit (Promega, E2520) according to the manufacturer's instructions. Luciferase activity was measured using a plate reader (Chameleon, Hidex) and luminescence was quantified from each assay well.

A test chemical is considered to be positive if the maximum response induced is equal to or exceeds $10 \%$ of the response of the positive control ( $1 \mathrm{nM}$ 17alpha-estradiol) in at least two of two or two of three runs.

\subsection{Study of the inertia of the material before and after treatment}

\subsubsection{Global migration}

The determination of the overall migration of the different samples was performed on the basis of the NF EN 1186-1 and EN 11863 standards.

The tests were carried out with total immersion contact in the liquid, namely simulant D1 [distilled water/ethanol - 50/50 v/v] for 10 days at $40^{\circ} \mathrm{C}$. The contact surface was $1 \mathrm{dm}^{2}$ taken from the bottom of containers made by the ESA. The test volume was $200 \mathrm{~mL}$. Three repetitions were performed.

\subsubsection{Specific migration of additives}

Contact details were identical to those applied in the global migration section. At the end of the contact period, the simulant was taken for the analysis of targeted molecules, more specifically Irganox 1076, Irgafos 168 and Tinuvin 326.

The analyzes were performed by gas chromatography coupled to mass spectrometry (GC-MS Clarus 500 - PerkinElmer). The column used was a HP-5MS ( $30 \mathrm{~m}$, diameter $0.25 \mathrm{~mm}$; stationary phase of $5 \%$ phenyl $/ 95 \%$ dimethyl polysiloxane).

The analytical conditions were as follows:

- Volume injected: $1 \mu \mathrm{L}$ in split mode.

- Programming injector temperature: $45-320^{\circ} \mathrm{C}$ with a ramp of $100{ }^{\circ} \mathrm{C} \mathrm{min}^{-1}$.

- Programming oven temperature: $50-330{ }^{\circ} \mathrm{C}$ with a ramp of $15^{\circ} \mathrm{C} \min ^{-1}$

\section{Results and discussion}

Following physical treatments, two types of studies were targeted, one based on the changes induced in the polymer matrix and the other on the reactivity of additives.

\subsection{Structural variations induced by different physical treatments}

Following microwave treatments ( 800 and $1100 \mathrm{~W}$ ), there was no significant change in the concentration of POSH in virgin experimental films (112-199 ppm). In contrast, the treatment with an electron-beam $100 \mathrm{kGy}$ showed that the POSH concentration had increased 10 times higher than that of the virgin PP film (1173 ppm). This increase could be attributed to a radiationinduced chain scission process in the PP matrix.

To check the potential protective effect of stabilizers on the degradation of $\mathrm{PP}$, and thus the formation of $\mathrm{POSH}$, previous experiments were repeated on experimental additivated films treated at $100 \mathrm{kGy}$. It was then observed that the concentration of POSH decreased in the presence of Irgafos 168 and Tinuvin 326 (918 and $514 \mathrm{ppm}$ respectively). This result confirms the protective effect of these stabilizers but it was interesting to note that this protection was more apparent with the UV absorber than with the antioxidant.

- Mechanical properties were measured on PP samples before and after irradiation treatments. The results show that the stress and deformation at yield were not significantly affected by irradiation, while deformation at break varied according to the treatment and the presence, or absence, of the additive. After a microwave treatment $(1100 \mathrm{~W})$, the stress at yield remained constant. However there was a decrease in the elongation at break of about $12 \%$ compared to the untreated film. No significant change was observed in the presence or absence of additives (here Tinuvin 326). Following an electron-beam (100 kGy) treatment, the stress and the elongation at break decreased by approximately 30\%. This decrease was less significant in the presence of Tinuvin 326 but it should be noted that the margin of error was high. These results reinforced the POSH observations that degradation of the polymer by chain
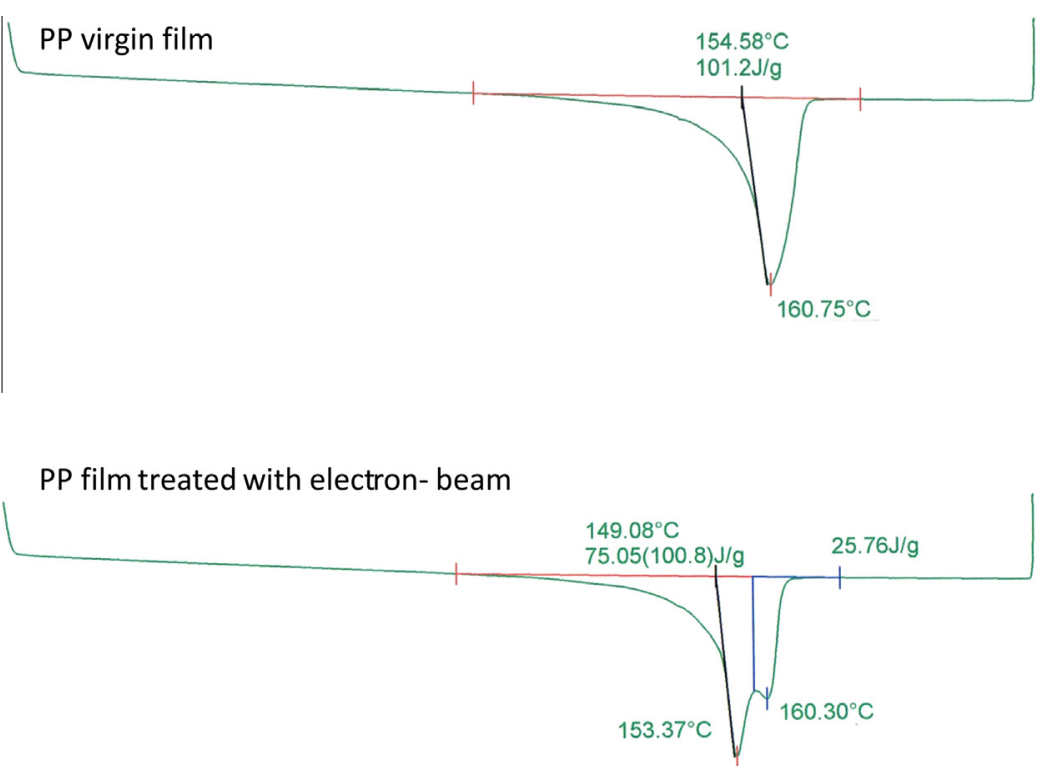

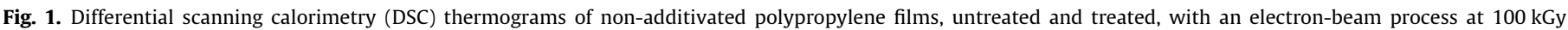
(second heating). 
scission occurred during the irradiation of PP and it was partially preserved by Tinuvin 326 . Stabilizers, limiting the formation of peroxyl-type free radicals and promoting their reactivity in the amorphous regions, may limit the degradation.

A sharp decrease of elongation at break after electron-beam treatment was consistent with findings in scientific literature (Lu \& Guan, 2000; Pawde \& Parab, 2011).

Deformation at break of semi-crystalline polymeric materials is often connected to the degree of crystallinity and the different crystalline phases of the polymer matrix. These characteristics are most often identified by thermal analysis.

Irradiation treatments did not significantly affect the percentage of crystallinity, meaning that the materials did not undergo irreversible changes. However there were changes in the thermogram after treatment by electron-beam (Fig. 1). The second PP scan (which basically is a measurement of the re-melting of the sample and thus the image of the polymer without its processing) showed a single melting peak $\left(160^{\circ} \mathrm{C}\right)$, suggesting that PP is characterized by one crystalline form (Yagoubi, Peron, Legendre, Grossiord, \& Ferrier, 1999). After exposing PP to a dose of $100 \mathrm{kGy}$, the melting peak became broader and the start of another peak was displaced to a lower temperature $\left(153^{\circ} \mathrm{C}\right)$. Similar behavior has been reported by several authors (Kokostoski, Stojanovic, \& Kacarevicpopovic, 1990; Riquet, Rohman, Guinault, \& Demilly, 2011). Changes to the peak for the electron-beam PP sample may have been due to crystalline reorganization during the $100-\mathrm{kGy}$ irradiation. The dual mode of the melting peaks may be attributed to structural changes. Multiple endotherms can be observed in a wide variety of semicrystalline polymers. This situation may arise from segregation effects linked to molecular weight, among other parameters (Perera, Albano, Gozalez, Silva, \& Ichazo, 2004).

\subsection{Additives degradation caused by different physical treatments}

To understand the effects of irradiation on the behavior of the targeted additives the potential impact of post-treatments on additives was established in standard solution, and then the additives were incorporated into the polymer matrix.

\subsubsection{Behavior of additives in standard solution}

3.2.1.1. Influence of the extraction procedures (DP, ASE). To determine the potential loss of additives from the extraction procedure, a known amount of each pure standard in ethyl acetate was divided into three parts: two, were DP or ASE treated and then analyzed by HPLC-DAD, and one was analyzed directly. The areas of the treated samples were compared to the area for the untreated sample, showing recoveries of $98 \%$ for Irgafos 168 and 96\% for Irganox 1010. No additional compounds or degradation products are expected to be formed during the extraction procedure due to degradation of the additives.

3.2.1.2. Influence of the physical treatments. Additives, in powder form, were treated by microwave and electron-beam. These compounds were then dissolved in ethyl acetate and analyzed by HPLC-DAD. No significant difference was found between additives treated compared to controls (data not shown) indicating that no significant degradation had occurred.

\subsubsection{Behavior of additives in experimental materials}

3.2.2.1. Extraction yield of additives before treatment of experimental materials. The results presented in Fig. 2a showed that the extraction yields were of the same range as the ASE or DP extractions regardless of the additive and the chosen methodology (HPLCDAD/GC-FID). (b) PP treated microwave 1100 Watt $\rightarrow$

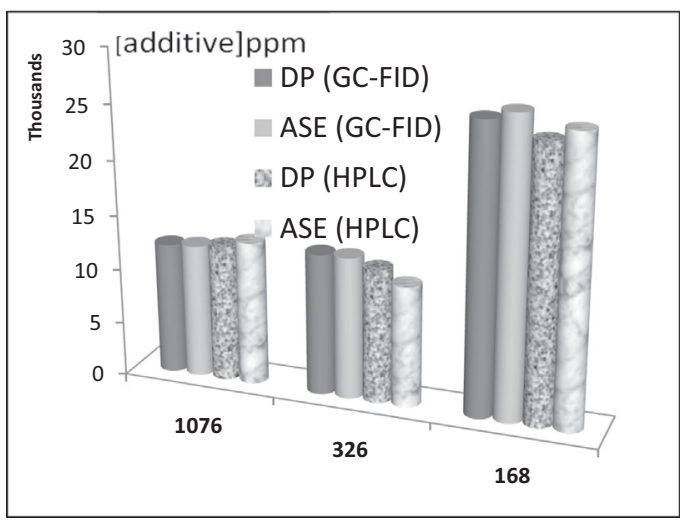

(a) virgin polypropylene (PP)
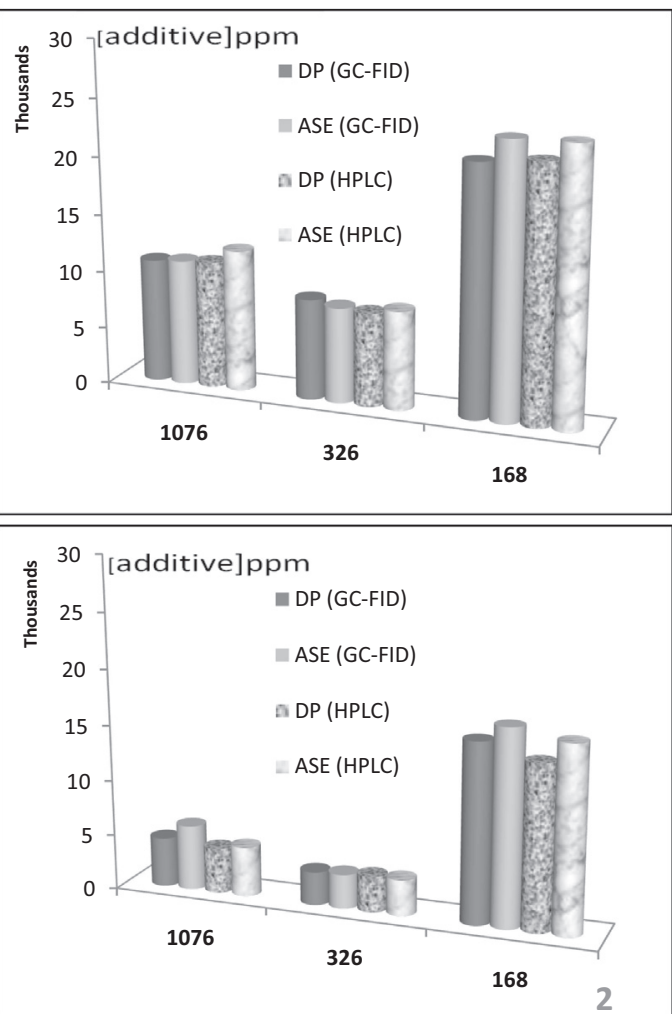

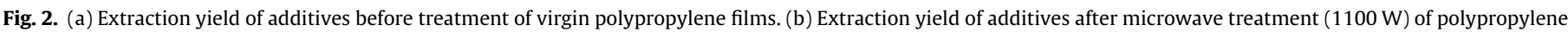

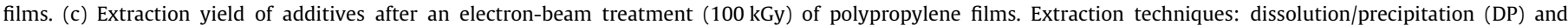

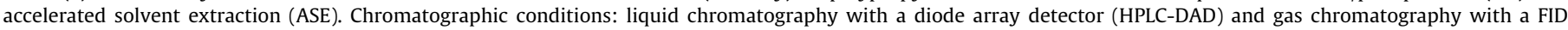
detector (GC-FID). 




Fig. 3. Percentage of additives (Irganox 1076, Tinuvin 326, and Irgafos 168) in untreated polypropylene films and polypropylene films treated with a microwave at 800 and $1100 \mathrm{~W}$ and polypropylene films with an electron-beam treatment at $100 \mathrm{kGy}$.

3.2.2.2. Extraction yield of additives after treatment of experimental materials. As noted earlier, the extraction yields were of the same order as the ASE or DP extractions (Fig. $2 \mathrm{~b}$ and c) regardless of the chosen methodology (HPLC-DAD/GC-FID). However, an interesting finding was that the pure standards did not degrade when treated by microwave or electron-beams in solution, whereas the additives embedded in polypropylene matrix degraded during irradiation treatments. This degradation depended not only on the nature of the additive but also on the type of irradiation treatment applied (Fig. 3). Thus, these results indicated that stabilizers were consumed or decomposed during the irradiation of polypropylene packaging due to interactions or reactions between polypropylene and the additives. The percentage of residual additive in experimental materials was significantly lower after electron-beam treatment $(100 \mathrm{kGy})$. Given the energy of this process $\left(2 \cdot 10^{5} \mathrm{eV}\right)$ compared to microwave $\left(10^{-2} \mathrm{eV}\right)$, it can be assumed that the degradation was most likely due to bond breaking. Indeed, according to scientific literature, a large proportion of stabilizers initially introduced into the materials could not be extracted from irradiated polyolefin (Krzymien et al., 2001). Losses depended on the absorbed dose and varied according to the nature and the initial amount of the stabilizer. Several studies have investigated the degradation products of stabilizers which may explain the reduced extraction rate. Decomposition products from the Irganox 1010 and Irganox 1076 in the ionized polypropylene $\gamma 10 \mathrm{kGy}$ extracts were then identified (Buchalla, Schüttler, \& Werner Bögl, 1993). These derivatives were produced when the original molecule broke up and retained a phenol moiety. As to the Irganox 1076, some compounds lost a tert-butyl group of the phenol ring. A benzoquinone compound, (2,6-di-tert-butyl-1, 4-benzoquinone), was also observed in the ionized polyolefin stabilized by Irganox 1010 (Bourges, Bureau, \& Pascat, 1993). The sharp reduction in the rate of Irgafos 168 extractable after irradiation could also be explained by the formation of derivatives. The oxidized form of Irgafos 168 , the 2,4-di-tert-butylphenol, and the 1,3-di-tert-butylbenzene, were observed in polypropylene stabilized with Irgafos 168 (Reingruber \& Buchberger, 2010). The treatment dose applied to the materials (1-25 kGy) may have been responsible for the different behaviors of the stabilizers and explains the non-detection of some compounds observed by some other authors. The lack of stoichiometric correlation between the loss of stabilizers of the formation of relevant degradation products suggests the formation of covalent bonds between certain products processing stabilizers to the polymer (Panagiotis, Frantz, \& Frank, 1999).

\subsubsection{Chemical characterization of extracts before and after physical} treatments. The chemical characterization of the extracts carried out by GC-FID did not show significant differences when using the extraction procedure, therefore only the results from ASE extraction will be presented here.

The method of analysis was based on GC-FID-MS because of the high separation power, large libraries of mass spectra and FID access providing similar responses for all organic compounds.

The compounds identified in the extracts from the experimental PP films can be seen in Table 1 .

Table 1

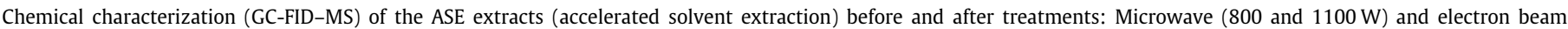
(100 kGy).

\begin{tabular}{|c|c|c|c|c|c|}
\hline \multirow[t]{2}{*}{ PP films } & \multirow[t]{2}{*}{ Compounds } & \multirow[t]{2}{*}{ Untreated (ppm) } & \multicolumn{2}{|c|}{ Microwave } & \multirow[t]{2}{*}{ E. Beam (100 kGy) (ppm) } \\
\hline & & & $800 \mathrm{~W}$ & $1100 \mathrm{~W}$ & \\
\hline \multirow{7}{*}{ PP 168} & Irgafos 168 & 27,600 & $\mathrm{D}$ & $\mathrm{D}$ & 10,470 \\
\hline & Tris-(2,4-di-tert-butyl-phenol)-phosphate & 825 & $\mathrm{D}$ & $\mathrm{D}$ & 518 \\
\hline & 1,3-Di-tert-butyl benzene & UD & UD & D & 114 \\
\hline & 2,4-Di-tert-butyl phenol & 163 & $\mathrm{D}$ & $\mathrm{D}$ & 2632 \\
\hline & Irgafos 168 after loss of two di-tert-butyl phenol & UD & UD & UD & 250 \\
\hline & Palmitic acid & $\mathrm{D}$ & $\mathrm{D}$ & $\mathrm{D}$ & $\mathrm{D}$ \\
\hline & Stearic acid & $\mathrm{D}$ & $\mathrm{D}$ & $\mathrm{D}$ & $\mathrm{D}$ \\
\hline \multirow[t]{8}{*}{ PP 1076} & Irganox 1076 & $\mathrm{D}$ & $\mathrm{D}$ & $\mathrm{D}$ & $\mathrm{D}$ \\
\hline & 2,6-Di-tert-butyl quinone & UD & D & D & D \\
\hline & 2,6-Di-tert-butyl phenol & $\mathrm{D}$ & $\mathrm{D}$ & $\mathrm{D}$ & $\mathrm{D}$ \\
\hline & $n$ Octadécane & UD & D & D & D \\
\hline & 1-Octadecanol & UD & D & D & D \\
\hline & 7,9-Di-tert-butyl-1-oxaspiro(4,5)deca-6,9-diene-2,8-dione & $\mathrm{D}$ & $\mathrm{D}$ & $\mathrm{D}$ & $\mathrm{D}$ \\
\hline & Palmitic acid & $\mathrm{D}$ & $\mathrm{D}$ & $\mathrm{D}$ & $\mathrm{D}$ \\
\hline & Stearic acid & $\mathrm{D}$ & $\mathrm{D}$ & $\mathrm{D}$ & $\mathrm{D}$ \\
\hline \multirow[t]{4}{*}{ PP 326} & Tinuvin 326 & $\mathrm{D}$ & $\mathrm{D}$ & $\mathrm{D}$ & $\mathrm{D}$ \\
\hline & Tinuvin 326 after loss of a $\mathrm{Cl}$ & UD & UD & UD & D \\
\hline & Palmitic acid & $\mathrm{D}$ & $\mathrm{D}$ & $\mathrm{D}$ & $\mathrm{D}$ \\
\hline & Stearic acid & $\mathrm{D}$ & $\mathrm{D}$ & $\mathrm{D}$ & $\mathrm{D}$ \\
\hline
\end{tabular}


additivated with Tinuvin 326.

UD undetected; D detected but not quantified; bold compounds generated by physical treatments. 
- Before irradiation, the analysis of PP extracts additivated with Irgafos 168 showed Irgafos 168 in its oxidized form as well as 2,4-di-tert-butylphenol (2,4-DTBP). After the $1100 \mathrm{~W}$ Microwave, and especially the $100 \mathrm{kGy}$, electron-beam irradiation treatments, the concentration of 2,4-DTBP increased markedly (163-2632 ppm) and we noted the presence of a new molecule: the 1,3-di-tert-butylbenzene (1,3-DTBB).

It was also noted that the transformation products that were detected (2,4-DTBP and 1,3-DTBB) might partially explain the stabilizer loss. These two compounds cannot be held totally accountable for the observed loss of Irgafos 168.

A compound which was detected, only after the electron-beam treatment, could correspond to Irgafos 168 after the loss of two di-tert-butylphenol ( $m / z$ 270) compounds.

Palmitic and stearic acids are additives which are commonly used in PP.

- 2,6-Di-tert-butylbenzoquinone and 1-octadecanol were identified after the irradiation of PP additivated with Irganox 1076, whether or not the treatment was made using microwaves or electron-beams. The first was probably a product of the oxidation of 2,6-di-tert-butylphenol, a by-product of Irganox 1076 identified in non-treated material, and the second would be a cleavage product of the additive's $\mathrm{CO}$ bond (Biedermann, Castillo, Riquet, \& Grob, 2014).

- As to the films enriched with Tinuvin 326, the main degradation product identified following an electron-beam treatment, seemed to be the result of a substitution of chlorine with hydrogen. This compound has the molecular mass of Tinuvin after the hydrogenation of a double bond.

The electron-beam treatment had a stronger impact on the polymer than the microwave one. It produced degradation products from the additives as well as from the polymer. The additives investigated reduced this degradation of the PP backbone significantly, but also formed degradation products themselves, the safety of which must be assured.

\subsection{Effect of irradiation treatments on materials: in vitro toxicity of the extracts}

\subsubsection{Cytotoxicity assay}

The cytotoxicity was assessed by measuring the RNA synthesis inhibition during a $30 \mathrm{~min}$ period. (Fig. 4A). Concerning the HepG2 cell line, under our experimental conditions the positive control Samples made with polypropylene without additives (NA) were not cytotoxic whatever the post-treatment used (microwave, electron beam or none). For samples with Irgafos 168 as an additive, only the electron-beam treatment led to a significantly strong cytotoxic effect (32\% of viability). This was probably due to the presence of a large quantity of 2,4-di-tert-butyl phenol $(2632 \mathrm{ppm})$ in that extract compared to its respective nonadditivated sample (163 ppm). When tested on its own, the 2,4di-tert-butyl phenol was also cytotoxic ( $<10 \%$ of viability) under the same conditions at its limit of solubility in the culture medium (100 mg/L).
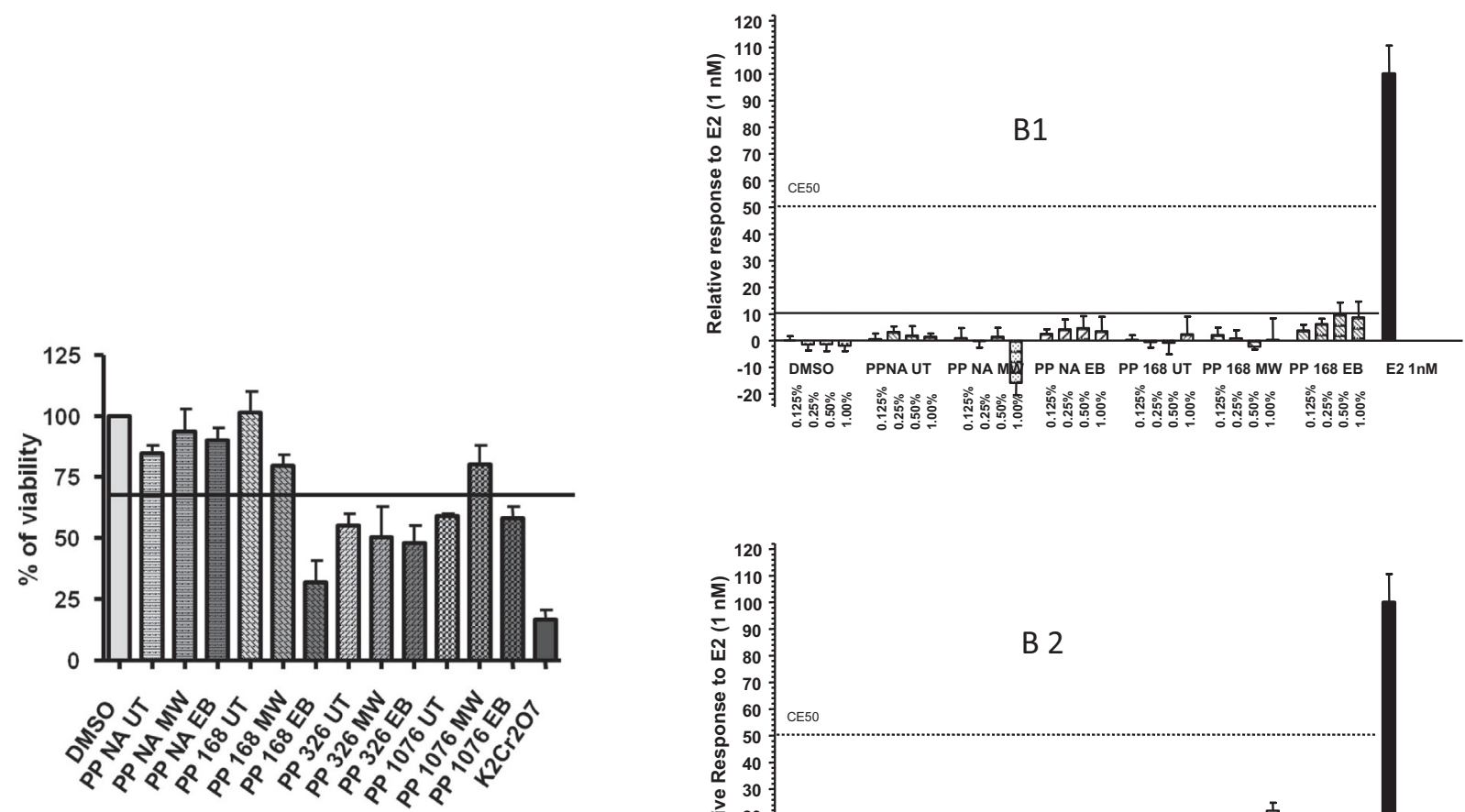

\section{A : Cytotoxicity effect}

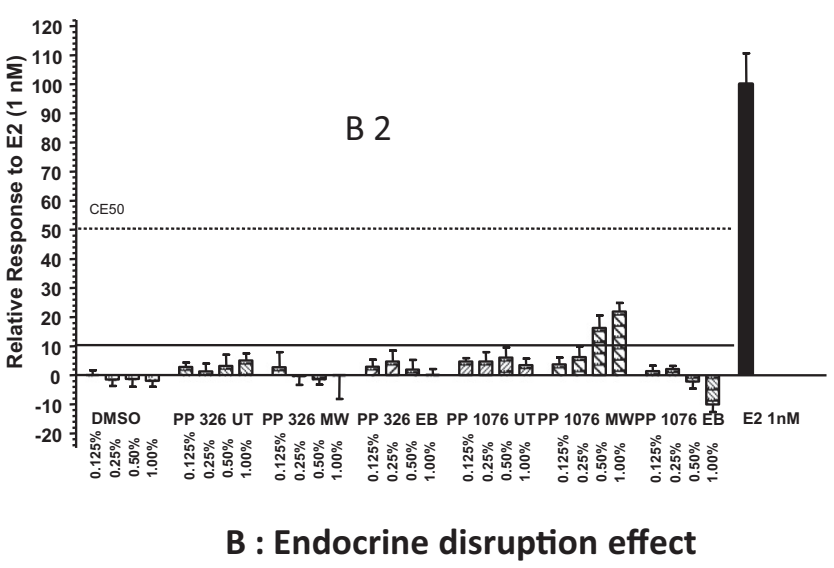

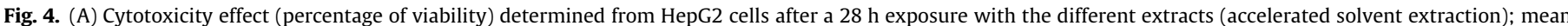

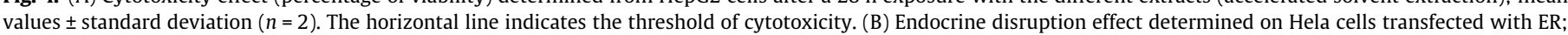

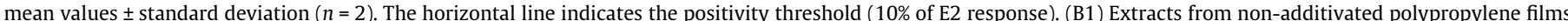

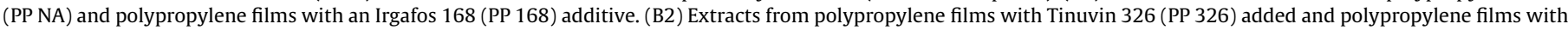
Irganox (PP 1076) added. 
As regards to the samples using Tinuvin 326 as an additive, a cytotoxic effect was observed (only $48 \%$ and $59 \%$ of cell viability) even in the absence of a treatment and without any differences no matter what post-treatment was used. Finally, for the polypropylene samples with Irganox 1076, only the microwave treatment did not induce a cytotoxic effect ( $80 \%$ of viability). The untreated samples (PP 1076 UT and PP 1076), the latter after an electron-beam treatment, were cytotoxic with a decrease of viability from $41 \%$ to $42 \%$ respectively. For the PP enriched with Tinuvin 326 and Irganox 1076, it was difficult to determine which compound could be responsible for the toxic effects observed as the compounds present in the extract were identified but not quantified. These preliminary results must be confirmed with a complementary analysis on the pure substances identified in the extracts and on other extracts from the same film formulation.

\subsubsection{The genotoxicity effect}

A score on 400 was calculated as a measure of the DNA damage in the comet assay in HepG2 cells exposed to the DMSO sample. The score of the positive control-treated cells (MMS at $50 \mu \mathrm{M}$ ) was 3.3-fold higher than the score of control cells as expected.

The results (data not shown) indicate that no extracts were found to be genotoxic right up to the highest solvent concentration tested $(0.5 \%, v / v)$ for the HepG2 cell line under the experimental conditions.

\subsubsection{Endocrine disruption effect}

The estrogenic effect was tested on hER $\alpha$-HeLa-9903 human cells following OECD Guideline No. 455.

Two samples, one with no additive and post-processed with a microwave treatment, and another one enriched with Irganox 1076 and post-processed with an electron-beam treatment, showed a high cytotoxicity at the highest concentration tested (1\%) (Fig. 4).

Among the twelve samples tested, only one, enriched with Irganox 1076 as an additive, and post-processed with a microwave treatment, showed a significant estrogenic activity with a concentration dependent effect of up to $1 \%$ (Fig. 4).

The assay was repeated two times on the same extracts and the results were reproducible. However, to explain the positive result of the bioassay, this assay should be performed on different extracts of PP enriched with Irganox 1076. There is also a need to quantify the compounds present in this extract and up to now, they have only been detected. The positive result obtained with
Irganox 1076 enriched PP could be due to the 2,6-DTBP detected in the extract. This compound must be tested on its own in this assay to check if it is at the origin of the positive effect.

Not surprisingly, after the electron-beam treatment, the PP 168 was negative. It contained 2,4-DTBP in great quantity, which is known to be an anti-androgenic compound in vitro (Satoh, 2007).

\subsection{The effect of irradiation treatments on the migration of additives}

The overall migration limit of plastic materials in contact with foodstuffs, established by Regulation (EU) No. 10/2011 is $10 \mathrm{mg} /$ $\mathrm{dm}^{2}$. Under the test conditions chosen, the values for all the samples were within this limit. However, there was a change in values based on the treatment applied to the material. Thus, when no treatment was applied, the overall level of migration was less than the method's detection limit $\left(<1 \mathrm{mg} / \mathrm{dm}^{2}\right)$. With the microwave treatment, measurable levels of global migration were obtained, but there were no significant differences according to the microwave power (Table 2). Only the material containing Irgafos 168 did not show any changes in the overall migration. Although the migrations were significantly higher using the electron-beam treatment, it is important to point out that the values obtained were still low given the tolerances of the analytical method $\left(2 \mathrm{mg} / \mathrm{dm}^{2}\right)$. However, it would be interesting to compare the data gathered with the results of other analytical method trends, especially the structural variations induced by different irradiation treatments. Indeed, the increase in the overall migration could be attributed to a radiation-induced chain scission process in the PP matrix ( $\mathrm{POSH}$ ) which resulted in the presence of oligomers in the extracts. Potential protective effects of stabilizers were not observed.

The positive list of Regulation 10/2011 sets out the specific migration limit values (SML) for the additives targeted in the study. Thus, the specific migration limit of Tinuvin 326 is set at $30 \mathrm{mg} / \mathrm{kg}$ and Irganox 1076 at $6 \mathrm{mg} / \mathrm{kg}$. As far as Irgafos 168 is concerned, the SML has not been specified so it has been set at $60 \mathrm{mg} / \mathrm{kg}$ by default were within these limits. As with global migration, there is a change in values depending on the treatment applied. Thus, for the PP 326, the specific migration value changed from 0.6 to $0.7 \mathrm{mg} / \mathrm{kg}$ during the $800 \mathrm{~W}$ microwave treatment and went up to $3.0 \mathrm{mg} / \mathrm{kg}$ when processing proceeded to $1100 \mathrm{~W}$.

These developments could indicate a significant influence of the power of the microwave treatment on the specific migration of this

Table 2

Global and specific migrations of polypropylene films before and after treatments: Microwave ( 800 and $1100 \mathrm{~W}$ ) and electron beam (100 kGy).

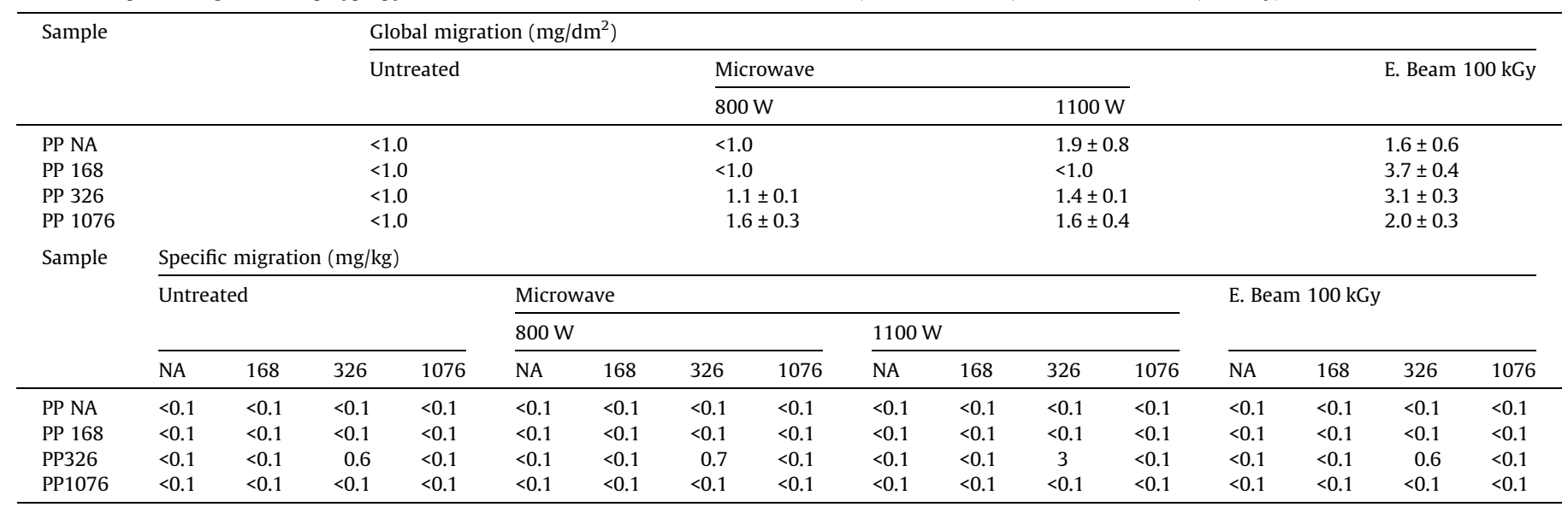


molecule. In contrast to the microwave treatment, the specific migration of Tinuvin 326 from the electron-beam treatment was the same as the control material $(0.6 \mathrm{mg} / \mathrm{kg})$. For other additives, specific migration levels remained below the method's detection limit and well below the SML set out in the regulations.

We previously mentioned the ability of the electron-beam treatment to significantly reduce the extractable levels of additives embedded in polypropylene matrix by degradation products (Fig. 2c) or by grafting on polymer chains. Therefore it is conceivable that observed reductions in extractability will result in particularly low specific migrations.

\section{Conclusion}

The objective of this article was to study the effects of two different radiation energy treatments on the physical, chemical and toxicological properties of antioxidants and their breakdown products of polypropylene.

Microwave treatments ( 800 or $1100 \mathrm{~W}$ ) do not lead to structural changes in polypropylene film studies. However, chemically speaking, no matter what power used, the GC-FID-MS analysis indicates the presence of novel degradation products in the film (Irgafos 168 and Irganox 1076).

Electron-beam $(100 \mathrm{kGy})$ treatments of polypropylene films have resulted in much greater chemical and structural changes.

Increasing the concentration of saturated hydrocarbons underlined the degradation of the polymer matrix, which was confirmed by significant changes found in the mechanical properties of the material. According to the inertial properties, levels of global migration increased significantly but still below the threshold stipulated by the regulations. The degradation products were more numerous and appeared in larger quantities than after undergoing a microwave treatment. In parallel, toxicological bioassays demonstrated the cytotoxic effects of the extracts. From a safety viewpoint, it would be useful to verify that the migration of these, when newly formed in foods, is below the thresholds of toxicological relevance.

This approach, which consists of assessing the toxicity of extracted substances alongside their chemical characterizations, is likely to enable a real technological leap into the assessment of the health risks of materials and objects in contact with foods. As emphasized previously, it may also facilitate the ability to comply with the regulations concerning the materials and objects which come into contact with food.

\section{Acknowledgment}

The authors gratefully acknowledge the financial support of ACTIA (Association de Coordination Technique pour l'Agroalimentaire).

\section{References}

Achilias, D. S., Giannoulis, A., \& Papageorgiou, G. Z. (2009). Recycling of polymers from plastic packaging materials using the dissolution-reprecipitation technique. Polymer Bulletin, 63, 449-465.

Aden, D. P., Fogel, A., Platkin, S., Damjarov, I., \& Knowles, B. B. (1979). Controlled synthesis of HBs Ag in a differentiated human liver carcinoma derived cell line. Nature, 282, 615-617.

Alin, J., \& Hakkarainen, M. (2011). Microwave heating causes rapid degradation of antioxidants in polypropylene packaging, leading to greatly increased specific migration to food simulants as shown by ESI-MS and GC-MS. Journal of Agriculture and Food Chemistry, 59, 5418-5427.

Alin, J., \& Hakkarainen, M. (2012). Migration from polycarbonate packaging to food stimulants during microwave heating. Polymer Degradation and Stability, 97, 1387-1395.

Bhunia, K., Sablani, S., Tang, J., \& Rasco, B. (2013). Migration of chemical compounds from packaging polymers during microwave, conventional heat treatment, and storage. Comprehensive Reviews in Food Science and Food Safety, 12, 523-545.
Biedermann, M., Castillo, R., Riquet, A. M., \& Grob, K. (2014). Comprehensive twodimensional gas chromatography for determining the effect of electron beam treatment of polypropylene used for food packaging. Polymer Degradation and Stability, 99, 262-273.

Biedermann-Brem, S., Kasprick, N., Simat, T., \& Grob, K. (2012). Migration of polyolefin oligomeric saturated hydrocarbons (POSH) into food. Food Additives and Contaminants A, 29, 449-460.

Bourges, F., Bureau, G., \& Pascat, B. (1993). Effects of electron beam irradiation on the migration of antioxidants and their degradation products from commercial polypropylene into food simulating liquids. Food Additives and Contaminants, 10 , 443-452.

Buchalla, R., Schüttler, C., \& Werner Bögl, K. (1993). Effects of ionizing radiation on plastic food packaging materials: A review. Part 1. Chemical and physical changes. Journal of Food Protection, 56, 991-997.

Davenas, J., Stevenson, I., Célette, N., Cambon, S., Gardette, J. L., Rivaton, A., \& Vignoud, L. (2002). Stability of polymers under ionising radiation: The many faces of radiation interactions with polymers. Nuclear Instruments and Methods in Physics Research B, 191, 653-661.

Fauris, C., Danglot, C., \& Vilagines, R. (1985). Rapidity of RNA synthesis in human cells. Water Resources, 19, 677-684.

Garrido-Lopez, A., Sancet, I., Montano, P., Gonzalez, R., \& Tena, M. T. (2007). Microwave-assisted oxidation of phosphite-type antioxidant additives in polyethylene film extracts. Journal of Chromatography A, 1175, 154-161.

Grob, K., Camus, P., Gontard, N., Hoellinger, H., Joly, C., Macherey, A. C., ... Ribera, D. (2010). Need for a better safety evaluation of food contact materials produced from resins. Food Control, 21, 763-769.

Jeon, J. Y., \& Kim, H. Y. (2000). Microwave irradiation effect on diffusion of organic molecules. European Polymer Journal, 36, 895-899.

Kirkland, D., Kasper, P., Müller, L., Corvi, R., \& Speit, G. (2008). Recommended lists of genotoxic and non-genotoxic chemicals for assessment of the performance of new or improved genotoxicity tests: A follow-up to an ECVAM workshop. Mutation Research, 653, 99-108.

Knasmuller, S., Mersch-Sundermann, V., Kevekordes, S., Darroudi, F., Huber, W. W., Hoelzl, C., ... Majer, B. J. (2004). Use of human-derived liver cell lines for the detection of mutagens and antimutagens. Mutation Research, 402, 185-202.

Knowles, B. B., Howe, C. C., \& Aden, D. P. (1980). Human hepatocellular carcinoma cell lines secrete the major plasma proteins and hepatitis B surface antigen. Science, 209, 497-499.

Kokostoski, D., Stojanovic, Z., \& Kacarevicpopovic, Z. (1990). The effect of antioxidants on the morphology of gamma irradiated isotactic polypropylene. Radiation Physics and Chemistry, 35, 190-196.

Krzymien, M. E., Carlsson, D. J., Deschênes, L., \& Mercier, M. (2001). Analyses of volatile transformation products from additives in $\gamma$ irradiate polyethylene packaging. Food Additives and Contaminants, 18, 739-749.

Lu, D. P., \& Guan, R. (2000). Structure and mechanical properties of isotactic polypropylene and IPP/talc blends functionalized by electron-beam irradiation. Polymer International, 49, 1389-1394.

Marqué, D., Feigenbaum, A., Dainelli, D., \& Riquet, A. M. (1998). Safety evaluation of an ionized multilayer plastic film used for vacuum cooking and meat preservation. Food Additives and Contaminants, 15, 831-841.

Nerín, C., Fernández, C., Domeño, C., \& Salafranca, J. (2003). Determination of potential migrants in polycarbonate containers used for microwave ovens by high-performance liquid chromatography with ultraviolet and fluorescence detection. Journal of Agricultural and Food Chemistry, 51, 5647-5653.

Panagiotis, G. D., Frantz, R., \& Frank, W. (1999). The effects of $\gamma$ irradiation on compositional changes in plastic packaging films. Packaging Technology and Science, 12, 119-130.

Pawde, S. M., \& Parab, S. (2011). Effect of electron beam irradiation on mechanical and dielectric properties of polypropylene films. Journal of Applied Polymer Science, 119, 1220-1229.

Perera, P., Albano, C., Gozalez, J., Silva, P., \& Ichazo, M. (2004). The effect of gamma radiation on the properties of polypropylene blends with styrene-butadienestyrene copolymers. Polymer Degradation and Stability, 85, 741.

Reingruber, E., \& Buchberger, W. (2010). Analysis of polyolefin stabilizers and their degradation products. Journal of Separation Science, 33(SI), 3463-3475.

Riquet, A. M., Delattre, J., Vitrac, O., \& Guinault, A. (2013). Design of modified plastic surfaces for antimicrobial applications: Impact of ionizing radiation on the physical and mechanical properties of polypropylene. Radiation Physics and Chemistry, 91, 170-179.

Riquet, A. M., Rohman, G., Guinault, A., \& Demilly, M. (2011). Surface modification of polypropylene by radiation grafting of hydrophilic monomers: Physicochemical properties. Surface Engineering, 27, 234-241.

Rivaton, A., Lalande, D., \& Gardette, J. L. (2004). Influence of the structure on the $\gamma$ irradiation of polypropylene and on the post-irradiation effects. Nuclear Instruments and Methods in Physics Research B, 222, 187-200.

Rivaton, A., Lalande, D., \& Gardette, J. L. (2005). Radiochemical ageing of ethylenepropylene-diene monomer elastomers. 4. Evaluation of some antioxidants. Polymer Degradation and Stability, 91, 136-143.

Satoh, K. (2007). Study on endocrine disruptive effects of chemicals in food with detection or possibility of detecting. Foods Food Ingredients Journal of Japan, 212.

Singh, N. P., McCoy, M. T., Tice, R. R., \& Schneider, E. L. (1988). A simple technique for quantification of low levels of DNA damage in individual cells. Experimental Cell Research, 175, 184-191.

Valentin-Séverin, I., Laignelet, L., Lhuguenot, J. C., \& Chagnon, M. C. (2002). Uridine uptake inhibition assay: An automated micromethod for the screening of cytotoxicity. Toxicology, 171, 207-213. 
Valentin-Séverin, I., Le Hégarat, L., Lebon, A. M., Lhuguenot, J. C., \& Chagnon, M. C. (2003). Use of HepG2 cell line for direct or indirect mutagens screening: Comparative investigation between comet and micronucleus assays. Mutation Research, 536, 79-90.

Westerink, W. M. A., \& Schoonen, W. G. E. J. (2007a). Cytochrome P450 enzyme levels in HepG2 cells and cryopreserved primary human hepatocytes and their induction in HepG2 cells. Toxicology in Vitro, 21, 1581-1591.
Westerink, W. M. A., \& Schoonen, W. G. E. J. (2007b). Phase II enzyme levels in HepG2 cells and cryopreserved primary human hepatocytes and their induction in HepG2 cells. Toxicology in Vitro, 21, 1592-1602.

Yagoubi, N., Peron, R., Legendre, B., Grossiord, J. L., \& Ferrier, D. (1999). Gamma and electron beam radiation induced physico-chemical modifications of poly (propylene). Nuclear Instruments E' Methods in Physics Research Section B, 151, 247-254. 